\title{
Polyurethane green composites for the treatment of boron present in the oil produced water
}

Murtuza Ali Syed ( $\sim$ smurtuzaali@gmail.com )

Caledonian College of Engineering https://orcid.org/0000-0003-2398-3436

Mohammed Al Sawafi

Caledonian College of Engineering

Feroz Shaik

Prince Mohammad Bin Fahd University

Research

Keywords: Polyurethane, Green composites, Oil produced water, Boron, PU/algae

Posted Date: April 22nd, 2020

DOI: https://doi.org/10.21203/rs.3.rs-22768/v1

License: (1) This work is licensed under a Creative Commons Attribution 4.0 International License.

Read Full License 


\section{Abstract}

Polyurethane (PU) based algae biocomposite is synthesized and tested for boron removal from oil produced water. The percentage of algae is varied in the biocomposite and its physical and chemical properties are evaluated. The surface morphology, crystalline structure, thermal stability is characterized using scanning electron microscope, fourier transform infrared spectroscopy and thermal gravimetric analysis. The density of synthesized PU/algae composites is in the range of 1.12 and $1.20 \mathrm{~g} / \mathrm{ml}$ based on content of filler in the PU matrix. Weight losses of the tested specimens in various chemical solutions are less than $10 \%$. The boron removal efficiency is in the range of $84-85 \%$, depending upon the algae filler at $\mathrm{pH} 7.19$.

\subsection{Introduction}

Oil industry worldwide produces large amounts of oil produced water (OPW). OPW accompanies with crude oil during the production process. OPW is highly saline with various inorganic and organic pollutants. The disposal of OPW is a big challenging task for oil producing companies. Treat and reuse of OPW is viable option other than injection to the oil wells in an enhanced oil recovery process (Feroz, et al., 2017). Boron is one of the major chemical contaminant in OPW (Ezerie, et al., 2012). The treated OPW for reuse should follow WHO standards of $0.5 \mathrm{mg} / \mathrm{L}$ (WHO, 2011). Treatment of boron in water and wastewater systems is a bit tedious (Bick and Oron, 2005). Various methods include reverse osmosis, adsorption, ion exchange, electro dialysis, electrocoagulation, and co-precipitation applied for the removal of boron from aqueous systems (Melnyk, et al., 2005, Turek, et al., 2007, Koseoglu, et al., 2010, Alper, et al., 2012, Jonna, et al., 2013, Ruiz, et al., 2013, Demey, et al., 2013). The combination of biomaterials with synthetic polymers is a good alternative to traditional products. This biocomposite will address the pertaining environmental and social issues in today's life (Murtuza, et al., 2010, Murtuza, et al., 2012). It is a great advantage that abundant available biomaterial such as algae can be utilized to produce valuable polyurethane polymer composite. Using algae as filler is having many advantages. Low cost, renewability, environmental friendly, non-toxic, high strength and low density (Tamara, et al., 2016, Ciecierska, et al., 2016). In the present research, an attempt is made to treat boron present in the oil produced water with synthesized polyurethane algae based biocomposite. The performance of adding the algae additives on PU properties is studied with different mass ratios. The characterization of the formed PU polymer with different algae composition is carried out to estimate the effects of amount of filler content on the density, chemical resistivity, crystalline structure and thermal stability.

\subsection{Materials And Methods}

\subsection{Materials}

Tolylene 2,4 Diisocyanates (TDI) of analytical grade (95\%), Dibutyltin dilaurate (DLDBT), Methyl isobutyl ketone (MIBK) is purchased from Sigma- Aldrich, Germany. Castor oil (CO) is procured from local markets. Castor oil is only the natural oil polyol available in the market, which is produced directly from a 
plant sources without chemical modifications. An alga is extracted from the sea rack, which is glued to the rock surface. The algae is dried and crushed into powder form. Before mixing algae with polymer, it was screened by sieve mesh size 300 micro to get uniform particle size. The filler density is estimated as $1.27 \mathrm{~g} / \mathrm{ml}$.

\subsection{Synthesis of PU/Algae biocomposites}

$50 \mathrm{ml}$ of methyl iso butyl ketone (MIBK) solvent is placed in the necked round bottom flask. Calculated amounts of tolylene 2,4 disocyanates (TDI), castor oil (CO) and 3 drops of catalyst dibutyltin dilaurate (DLDBT) are added to MIBK solvent as per standard procedure (Madhukar, et al., 2015). The flask is then kept on digital hot plate fitted with a condenser. The temperature is maintained between $60-70^{\circ} \mathrm{C}$ and stirred at 1200 RPM. The reaction between the aromatic TDI isocyanates, which is having two isocyanates groups (NCO) and a hydroxyl group (present in the castor oil) in the presence of catalyst DLDBT produce urethane groups as shown in the equation 1.

\section{ROH+R'NCO $\rightarrow$ ROCONHR' (1)}

The algae powder is added to the PU solution after 30 minutes of mixing with different polymer-algae weight ratios (100/0, 97.5/2.5, 95/5, 92.5/7.5 and 90/10). PU/algae is stirred again for 1 hour. The resulting viscous solution poured into clean glass mold of dimension of $20 \times 10 \times 4 \mathrm{~cm}$ to get the uniform polymer film. The solution is cooled and dried slowly under ambient temperature overnight. The created $\mathrm{PU}$ sheet in the glass mold has been post cured in the electric oven at $60^{\circ} \mathrm{C}$ for 5 hours. The prepared biocomposite sheets are taken out and stored for characterization and experimentations.

\subsection{Collection of OPW}

Oil Produced water (OPW) is collected from (Oxy-Oman) site (Makizina) for this experimental purpose. Mukhaizna field is located in Oman's south central interior and it is producing very high viscosity oil. The initial boron and other multi component concentrations areestimated using plasma atomic emission spectrometry (ICP). The initial boron concentration in the produced water is obtained as $6.44 \mathrm{mg} / \mathrm{l}$. The initial $\mathrm{pH}$ value of OPW sample is measured as 7.19.

\subsection{PU/Algae Characterization}

ASTM D792-08 method is used to determine the experimental density of the specimens. The weight of the specimen is taken in the air and in immersed water at room temperature to determine the specific gravity. Accordingly calculated the density of PU/Algae polymer specimens. The theoretical density is calculated for thecomposites by the weight additive principle as shown in equation 2Madhukar, et al., 2015). 
$\rho=\omega 1+\omega 2(2)$ Where $\rho$ is the density of composite, $\omega_{1}, \rho_{1}, \omega_{2}, \rho_{2}$ are the weight fraction, thedensity of the filler and neat polymer respectively.

The chemical resistance of PU/Algae polymer composites is studied in the various chemical reagents such as acids, basis, salts and organic solvents. Uniform surface area of PU/Algae composites istaken and immersed in the prepared chemical solutions for 7 days under laboratory environment. After 7 days, the specimens are removed and wiped with tissue papers and weighted. Then, the percentage weight changes are calculated. Also, surface to mass of the specimens are estimated. The morphological behavior, chemical composition and crystalline structure of the PU/algae composites is investigated by using scanning electron microscopy (SEM) technique with an operating voltage of $15 \mathrm{kV}$, magnification of $1000 x$ and quality resolution of 10 microns. FTIR spectroscopy is used to analyze the physiochemical properties of synthesized PU/Algae composites as per standard procedure in the range of wave number 600 to $4000 \mathrm{~cm}^{-1}$ (Marek, 1993).

A thermal property of polymer is investigated by using thermal gravimetric analysis (TGA) in order to determine the test conditions and the behavior of the polymer with increasing temperature. The sample is cut into a small piece and after that loaded into sample ceramics pan to complete thermal analysis. The nitrogen gas grade 5 is used as purge gas and it is supplied at aconstant flow rate $100 \mathrm{ml} / \mathrm{min}$. The thermal analysis in TGA is started in the temperature range between 32 and $38^{\circ} \mathrm{C}$ and the final temperature considered for this analysis is $800^{\circ} \mathrm{C}$. The heating rate is customized at $10^{\circ} \mathrm{C} / \mathrm{min}$. The thermograms are interpreted for all composites by using TA instrument explorer software universal V4.7A.

\subsection{Boron adsorption characteristics}

The treated oil produced water (OPW) is analyzed to examine the boron adsorption efficiency for different $\mathrm{PU} /$ algae composites. The adsorbent dosage is fixed as $1 \mathrm{gram}$ in $50 \mathrm{ml}$ of OPW for all PU compositions. The agitation is adjusted at 100 RPM to assist the contact between adsorbent and theuntreated OPW for $72 \mathrm{hrs}$. The final boron concentration is obtained using plasma atomic emission spectrometry (ICP) and then the removal efficiencies are estimated.

\subsection{Results And Discussion 3.1 Physical Properties}

Three specimens are taken from each sample to determine the average density of PU/Algae compositions. The changes in density in a single polymer sheet are due to localized differences in crystalline structure, loss of plasticizer, absorption of methyl iso butyl ketone solvent and differences in algae filler compositions. The densities of neat polymer and algae filler estimated as $1.124 \mathrm{~g} / \mathrm{ml}$ and 1.27 $\mathrm{g} / \mathrm{ml}$ respectively. Both theoretical and experimental values for the PU/algae green composites is estimated and tabulated in Table 1. The densities estimated are in the range of 1.12 and $1.20 \mathrm{~g} / \mathrm{ml}$ based 
on thecontent of the filler in the PU matrix. The density is increases with an increase of the filler in green composite due to the restriction of soft PU to pass through the tiny space between the rigid filler particles. The experimental results are slightly higher than theoretical results. This is due to the aggregation of filler at a higher amount of the filler content and maybe the filler not wetted completely in the PU matrix (Madhukar, et al., 2015). The surface area of the uniform mass of specimens is decreases with an increase in the filler content. This may be due to the passage of the high density filler into the gaps of the PU matrix. Hence, the higher filler content polymer has less surface area compared to the analogous mass of less filler content polymer.

Table1: Physical properties of PU/algae composite

\begin{tabular}{|c|c|c|c|c|}
\hline \multirow{2}{*}{$\begin{array}{c}\text { PU/algae } \\
\text { compositions }\end{array}$} & \multicolumn{2}{|c|}{ Density (g/ml) } & $\begin{array}{c}\text { Void } \\
\text { content } \\
\text { (\%) }\end{array}$ & $\begin{array}{c}\text { Surface to mass of the } \\
\text { specimens }\left(\mathbf{c m}^{\mathbf{2}} / \mathbf{g}\right)\end{array}$ \\
\cline { 2 - 3 } & Experimental & Theoretical & 0 & 31.25 \\
\hline $100 / 0$ & 1.122188 & 1.122188 & 0.67 \\
\hline $97.5 / 2.5$ & 1.126353 & 1.125883 & 0.0004 & 24.09 \\
\hline $95 / 5$ & 1.162581 & 1.129578 & 0.0284 & 21.86 \\
\hline $92.5 / 7.5$ & 1.206 & 1.133273 & 0.0603 & 21.16 \\
\hline $90 / 10$ & 1.208182 & 1.136969 & 0.0589 & \\
\hline
\end{tabular}

\subsection{Chemical Resistivity}

The chemical resistivity of synthesized PU/algae polymer composites is studied in the various chemical reagents. The chemical resistivity study helps to understand, the applicable uses of the PU/algae. It shows to what extent the algae powder can stay in touch with the PU specimen under various chemical environments. The weight losses for different PU/Algae specimens are obtained after 7 days are shown in Table 2. The percentage weight losses of the tested samples in the various chemical agents are within acceptable limit which is less than $10 \%$. Furthermore, it is observed that PU/algae composites are dissolved rapidly in the acidic and basic solution than other chemical solutions. There is no significant change in surface color and thickness of the PU/algae specimens in the various tested chemical solutions.

Table 2: Chemical resistivity of PU/algae composites 


\begin{tabular}{|l|c|c|c|c|c|}
\hline & \multicolumn{5}{|c|}{ Weight Loss for PU/algae Composition } \\
\hline Chemical Reagent & $\mathbf{1 0 0 / 0}$ & $\mathbf{9 7 . 5 / 2 . 5}$ & $\mathbf{9 5 / 5}$ & $\mathbf{9 2 . 5 / 7 . 5}$ & $\mathbf{9 0 / 1 0}$ \\
\hline $5 \%$ Sodium Hydroxide, $\mathrm{NaOH}$ & 2.87 & 5.24 & 4.0 & 7.73 & 6.55 \\
\hline $5 \%$ Sulfuric Acid, $\mathrm{H}_{2} \mathrm{SO}_{4}$ & 1.98 & 5.65 & 4.96 & 6.50 & 6.31 \\
\hline $5 \%$ Ethanol, $\mathrm{C}_{2} \mathrm{H}_{6} \mathrm{O}$ & 0.5 & 2.13 & 2.69 & 1.42 & 1.92 \\
\hline $5 \%$ Methanol, $\mathrm{CH}_{3} \mathrm{OH}$ & 1.08 & 2.47 & 0.65 & 1.05 & 1.87 \\
\hline $5 \%$ Sodium Carbonate, $\mathrm{Na}_{2} \mathrm{CO}_{3}$ & 0.18 & 0.25 & 0.30 & 0.55 & 0.21 \\
\hline
\end{tabular}

\subsection{Surface Morphology}

The SEM images of different PU/algae composites are shown in Figures 1(A)-1(E). SEM images indicate that algae powder have been distributed and integrated properly in the PU matrix. The $5 \%$ of filler weight in the PU matrix (Figure 1C) is distributed uniformly compared to the other filler composites. All the SEM images shown good adhesion of the filler into PU matrix. It is observed, the roughness and deformation of the polymers increased with an increase of the algae filler content. It may be due to the restriction of soft PU to pass through the tiny space between the rigid filler particles.

\subsection{FTIR Studies}

FTIR spectra of PU/algae composites are shown in Figure 2. Most of the synthesized biocomposite polymers shown the absence of the peak between 2270 and $2280 \mathrm{~cm}-1$ indicating that no free NCO groups (Tamara, et al., 2016). All the isocyanate groups have reacted during the polymerization process. Furthermore, NCO group peak areas are increased slightly with an increase of algae mass ratio. This indicates the reactivity of urethane $\mathrm{NCO}$ group decreases with an increase in the algae green composition. $\mathrm{OH}$ group peaks are not observed for all the developed polymer composites as shown in the Figure 2. Complete reaction of $\mathrm{OH}$ group with isocyantes groups. It is also observed absence of Urethane $\mathrm{C}=\mathrm{O}$ vibration in the range of $1720-1730 \mathrm{~cm}-1$ for the $7.5 \%$ algae content and appearance of $\mathrm{C}=\mathrm{C}$ aromatic vibration in the all the synthesized PU/algae composites. Table 3 illustrates the expected range of the peaks of FT-IR spectra of PU/Algae composites and the observed peaks from the estimated curves.

\section{Table 3: FTIR spectroscopy peaks of PU/algae composites}




\begin{tabular}{|c|c|c|c|c|c|c|}
\hline \multirow{2}{*}{ Group } & \multirow{2}{*}{ Expected Peak $\left(\mathrm{cm}^{-1}\right)$} & \multicolumn{5}{|c|}{ Observed Peak $\left(\mathrm{cm}^{-1}\right)$} \\
\cline { 3 - 6 } & & 0 & 2.5 & 5 & 7.5 & 10 \\
\hline NCO Vibration & $2270-2280$ & None & None & None & None & None \\
\hline C=O Vibration & $1700-1750$ & 1726 & 1725 & 1726 & 1701 & 1726 \\
\hline Urethane -C=O Vibration & $1720-1730$ & 1726 & 1725 & 1726 & None & 1726 \\
\hline C=C aromatic Vibration & $1520-1600$ & 1533 & 1533 & 1533 & 1528 & 1530 \\
\hline C-H stretching & $2840-3000$ & 2922 & 2923 & 2923 & 2922 & 2923 \\
\hline OH vibration & $3530-3550$ & None & None & None & None & None \\
\hline
\end{tabular}

\subsection{Thermogravimetric analysis}

TGA is used to estimate the thermal stability of the PU/algae composites. The obtained thermograms are shown in Figure 3. The TGA thermograms indicated that PU matrix with different mass content of algae are stable up to $70-75^{\circ} \mathrm{C}$. The PU/algae composite degradation can be described in three stages. First stage at temperature range of $75-251.80^{\circ} \mathrm{C}$, the sample loses about $5.29 \%$ of its initial weight due to the gradual evaporation of the methyl iso butyl ketone solvent and the slight degradation of the soft segment in the PU/algae composite. Second stage at temperature range of $251.80-520^{\circ} \mathrm{C}$, the sample losses about $88.46 \%$ of its weight attributed to thermal degradation of the hard segment and partially degradation of the algae component. Finally, the third stage starting at temperature $520^{\circ} \mathrm{C}$ up to upper limit temperature considered for this study $\left(800^{\circ} \mathrm{C}\right)$, the sample loses about $2.14 \%$ of total weight due to decomposition of the algae composite and degradation of the remains hard segment and other associated compartments. More algae content has less weight loss, which indicates that algae can act as good filler for thermal degradation stability of PU polymer.

The relative thermal stability of the PU matrix with different algae content is estimated by comparing the decomposition temperatures at different weight loss percentages as shown in Table 4. The T0 is expressing the temperature of onset decomposing, whereas T10, T20, T50 and T70 expressing the decomposition temperature at 10, 20, 50, 70 weight loss percentage. The temperature of degradation of $\mathrm{PU} /$ algae composites is increased with an increase of algae content at different weight loss percentages. This lead to conclude that filler content is improving the relative thermal stability of the PU polymer. It can be act as a thermal insulator due the ability to block the volatile component during the thermal degradation analysis process.

Table 4: Effect of algae filler on the thermal stability of the PU matrix 


\begin{tabular}{|c|c|c|c|c|c|c|}
\hline Algae content in PU matrix & Sample weight $(\mathrm{mg})$ & \multicolumn{5}{|c|}{ Temperature at different weight losses } \\
\cline { 3 - 6 } & & $\mathrm{T}_{0}$ & $\mathrm{~T}_{10}$ & $\mathrm{~T}_{20}$ & $\mathrm{~T}_{50}$ & $\mathrm{~T}_{70}$ \\
\hline 0 & 24.775 & 70 & 278 & 298 & 382 & 438 \\
\hline 2.5 & 24.593 & 71 & 278 & 297 & 378 & 437 \\
\hline 5 & 27.81 & 73 & 278 & 299 & 383 & 440 \\
\hline 7.5 & 23.785 & 74 & 280 & 300 & 386 & 442 \\
\hline 10 & 23.474 & 75 & 280 & 301 & 386 & 443 \\
\hline
\end{tabular}

\subsection{Boron adsorption studies}

The boron removal from OPW is estimated for different PU/algae composites after 72 hours of contact time as shown in Table 5. The removal efficiency is in the range of 84 to $85 \%$. The maximum boron removal efficiency is observed in case of neat PU polymer as adsorbent due to absence of filler and availability of space between PU matrix molecules. However, there is not much difference between the different PU/algae composites for boron removal efficiency. Figure 4 represents the boron presence in $\mathrm{OPW}$ after treating with various PU/algae matrix.

Table 5: Boron adsorption efficiency of the PU/algae composites

\begin{tabular}{|c|c|c|c|c|c|}
\hline $\begin{array}{c}\text { PU/Algae } \\
\text { composition } \\
\%\end{array}$ & $\begin{array}{c}\text { Contact } \\
\text { time } \\
(\mathrm{hr})\end{array}$ & $\begin{array}{c}\text { Initial boron } \\
\text { concentration } \\
(\mathrm{mg} / \mathrm{l})\end{array}$ & $\begin{array}{c}\text { Final boron } \\
\text { concentration } \\
(\mathrm{mg} / \mathrm{l})\end{array}$ & $\begin{array}{c}\text { mg B } \\
\text { removal/g } \\
\text { adsorbent }\end{array}$ & $\begin{array}{c}\text { Removal } \\
\text { efficiency } \\
(\%)\end{array}$ \\
\hline $100 / 0$ & 72 & 6.44 & 0.958 & 5.482 & 85 \\
\hline $97.5 / 2.5$ & 72 & 6.44 & 0.987 & 5.453 & 84 \\
\hline $95 / 5$ & 72 & 6.44 & 0.989 & 5.451 & 84 \\
\hline $92.5 / 7.5$ & 72 & 6.44 & 0.982 & 5.458 & 84 \\
\hline $90 / 10$ & 72 & 6.44 & 1.02 & 5.42 & 84 \\
\hline
\end{tabular}

\subsection{Conclusions}

This study investigated the performance of algae based PU polymer composites for the treatment of boron presence in oil produced water (OPW). PU/algae composites synthesized by varying the content of filler algae and their physical and chemical properties are estimated. The density of PU/algae composites is in the range of 1.12 and $1.20 \mathrm{~g} / \mathrm{ml}$ based on content of filler. The density increases with an increase in algae content. The surface area decreased with an increase in the filler content of the uniform mass of PU/algae composites. Weight loss of the tested specimens in various chemical solutions are less than $10 \%$, indicated stable chemical resistance by PU/algae biocomposites. SEM images showed the 
proper distribution and integration of algae filler in PU matrix. The roughness and difficulty for deformation increases with filler content. FTIR spectroscopy indicates the absence of NCO peaks which indicates there is no free NCO group in the formed polymers. Thermogravimetric analysis showed with increases in filler content, the thermal stability increased. The boron removal efficiency is found to be in the range of $84 \%$ and $85 \%$ at $\mathrm{pH} 7.19$.

\subsection{References}

1. Feroz, S., Khalid Al Saadi., Nageswara Rao, L., Varghese, M. 2017. Performance studies on solar photocatalysis and photo fenton process in treatment of polymer-based oil produced water, International Journal of Photochemistry. 3:1-6.

2. Ezerie, H. E., Mohamed, H. I., Shamsul, R. B. M. K. 2012. Boron in produced water: challenges and improvements: A comprehensive review, Journal of applied sciences. 12(5):402-415.

3. Boron in drinking water, WHO Guidelines for drinking water quality, 2011. World Health Organization.

4. Bick, A., Oron, G. 2005. Post-treatment design of seawater reverse osmosis plants; boron removal technology selection of potable water production and environmental control, Desalination. 178:233246.

5. Koseoglu, H., Harman, B. L., Yigit, N. O., Guler, E., Kabay, N., Kitis, M. 2010. The effects of operating conditions on born removal from geothermal waters by membrane processes, Desalination. 258 (13): 72-78.

6. Alper, E. Y., Recep, B., Serkan, B., Baybars, A. F., Mehmet, M. K. 2012. Boron removal by means of chemical participation with calcium hydroxide and calcium borate formation, Korean. J. Chem. Eng. 29(10):1382-1387.

7. Demey, H., Vincent, T., Ruiz, M., Sastre, A.M., Guibal, E. 2013. Development of a new chitosan/ $\mathrm{Ni}(\mathrm{OH}) 2$-based sorbent for boron removal, Chemical Engineering Journal. 244:576-586.

8. Ruiz, M., Tobalina, C., Demey-Cedeno, H., Barron-Zambrano, J. A. Sastre, A.M. 2013. Sorption of boron on calcium alginate gel beads, Reactive Function Polymers. 73:653-657.

9. Joanna, W. Marek, B. 2013, Methods of boron removal from aqueous solutions, Desalination. 310:18-24.

10. Melnyk, L., Goncharuk, V., Butnyk, l., Tsapiuk, E. 2005. Boron removal from natural and wastewaters using combined sorption membrane process, Desalination. 185:147-157.

11. Turek, M., Dydo, P., Trojanowska, J., Campen, A. 2007. Adsorption/Co-precipitation-reverse osmosis system for boron removal, Desalination. 205:192-199.

12. Murtuza, A. S., Siddaramaiah., Raihan, T. S., Akheel. A. S. 2010. Investigation on physico-mechanical properties, water, thermal and chemical ageing of unsaturated polyester/turmeric spent composites, Polymer-Plastics Technology and Engineering. 49(6):555-559.

13. Murtuza, A. S. Akheel, A. S. 2012, Development of a new inexpensive green thermoplastic composite and evaluation of its physic-mechanical and wear properties, Materials \& Design. 36: 421-427. 
14. Tamara Calvo-Correas., Nagore Gabilondo., Ana Alonso-Varona., Teodoro Palomares., Angeles Corcuera, M., Arantxa Eceiza. 2016. Shape-memory properties of crosslinked biobased polyurethanes, European Polymer Journal. 78:253-263.

15. Ciecierska, E., Jurczyk-Kowalska, M., Bazarnik, P., Gloc, M., Kulesza, M., Kowalski, M., Krauze, S., Lewandowska, M. 2016, Flammability, mechanical properties and structure of rigid polyurethane foams with different types of carbon reinforcing materials, Composite Structures. 140:67-76.

16. Madhukar, B. S., Bhadre Gowda,D. G., Siddaramaiah., Somashekar, R. 2015, Evaluation of mechanical, thermal, and morphological behaviors of polyurethane/mahua seed cake green composite, Advances in Polymer Technology. 36(2):186-195.

17. Marek, W. U. 1993. Fourier transform infrared and fourier transform Raman spectroscopy of polymers, Structure-Property Relations in Polymers, Chapter 1: 3-40.

\section{Declarations}

Availability of data and materials: All the necessary data and materials are available.

Competing interest: Authors do not have any competing interest.

Funding: No funding is received in this research work.

Authors contribution: Mr. Mohammed Al Sawwafi carried out experimental work, Dr. Murtuza Ali Syed contributed in characterization and analysis. Dr. Shaik Feroz contributed in interpretation of data.

Acknowledgement: Authors would like to thank Caledonian college for providing the facilities.

\section{Figures}



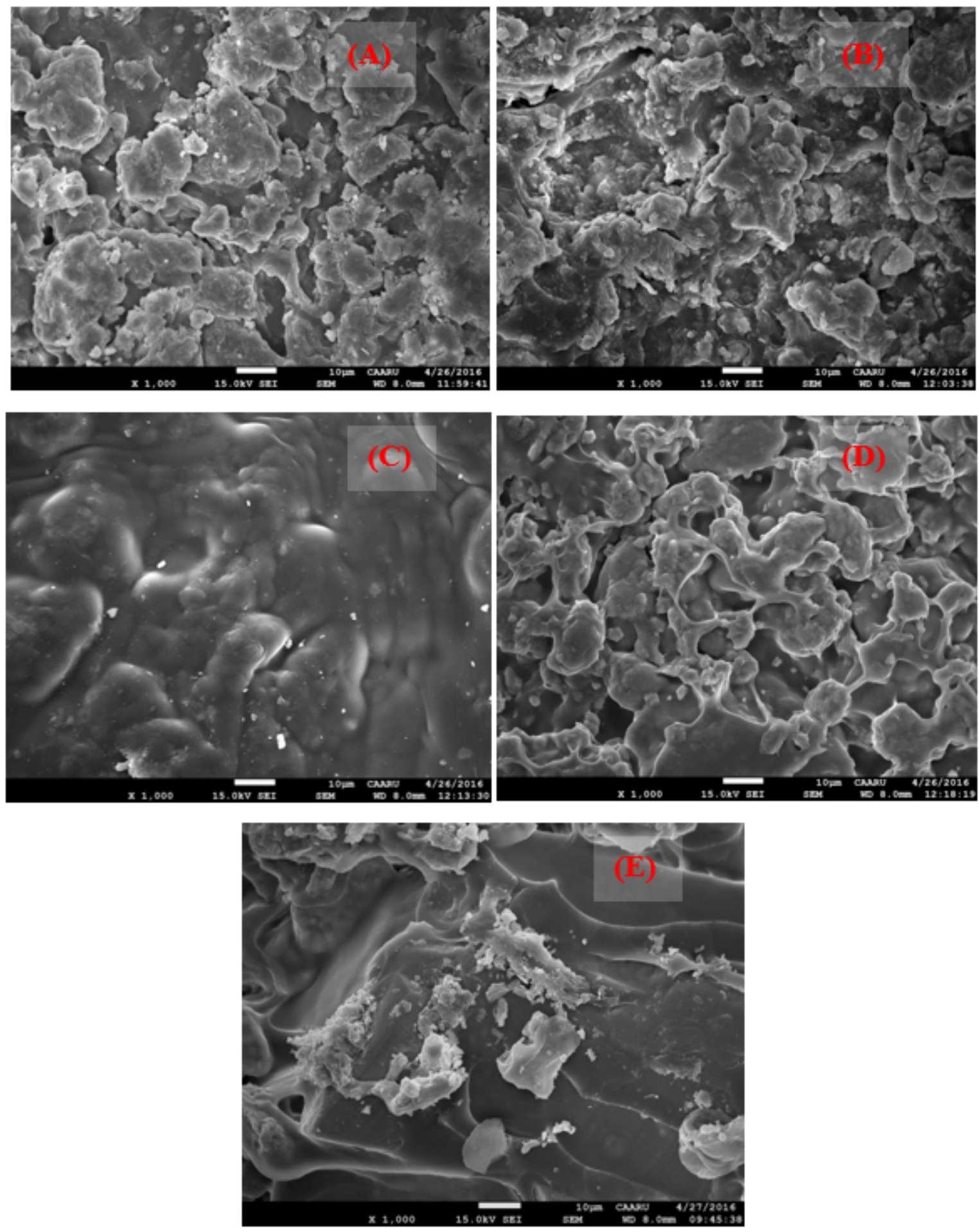

\section{Figure 1}

SEM images of PU green composites with (A) $0 \%$, (B) $2.5 \%$, (C) $5 \%$, (D) $7.5 \%$ and (E) $10 \%$ of algae filler 


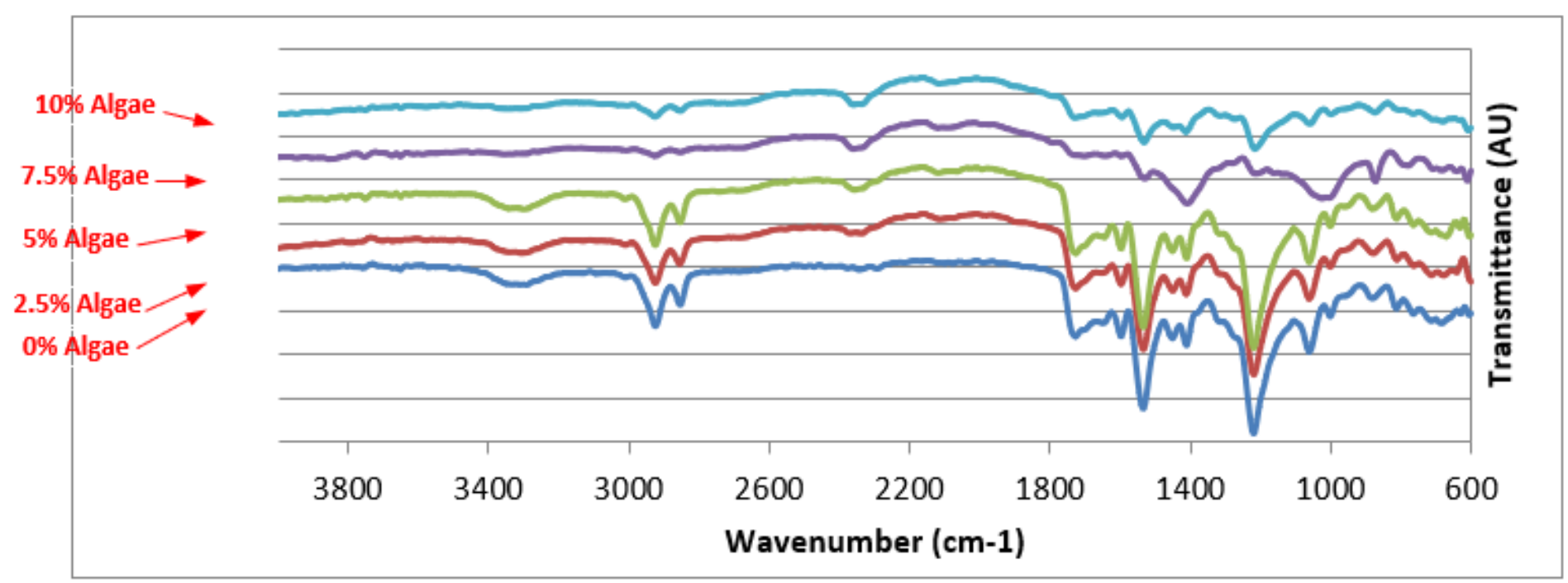

Figure 2

FTIR Spectra of PU/algae Composites

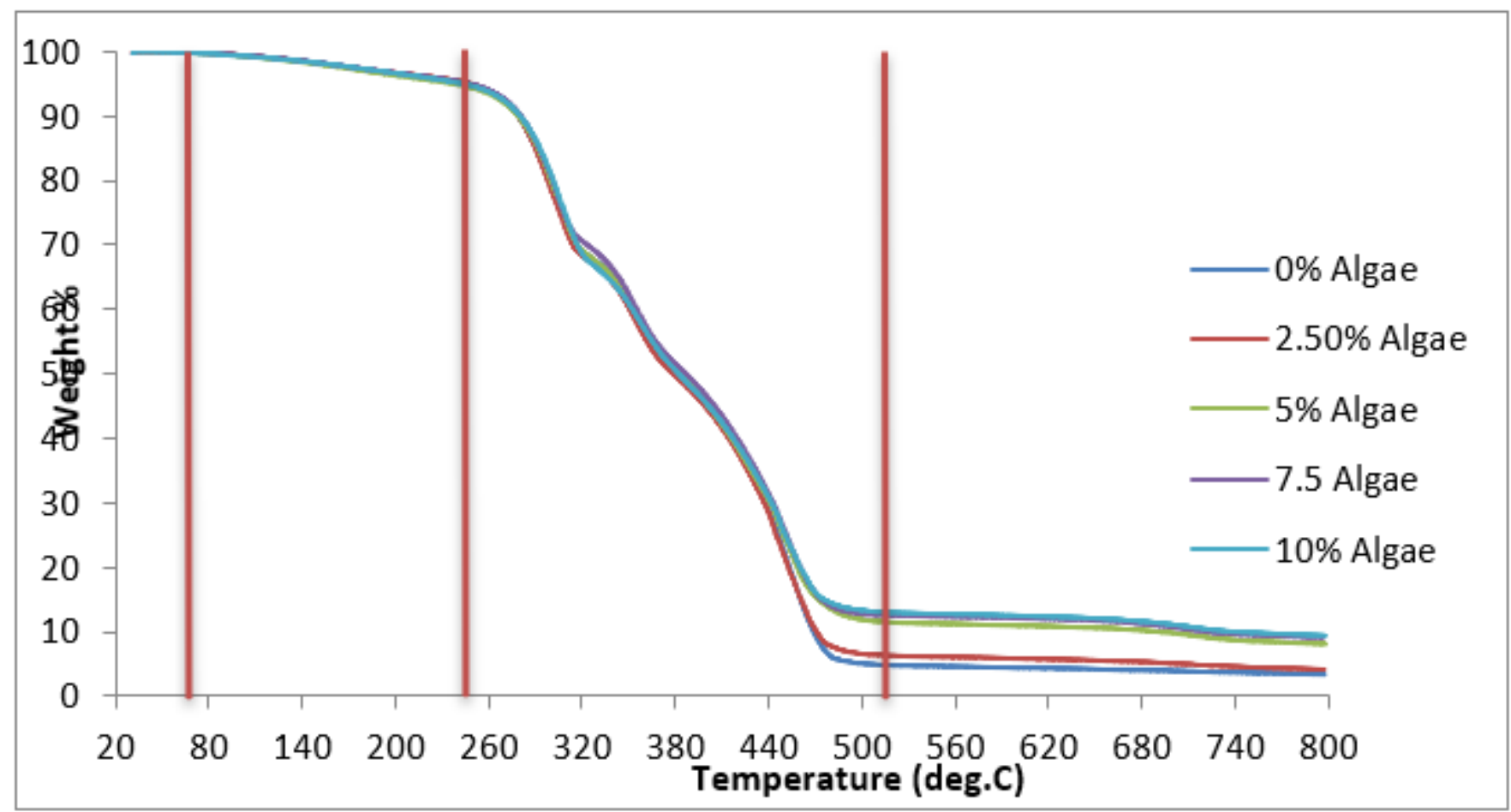

Figure 3

Thermograms of PU/algae composities 


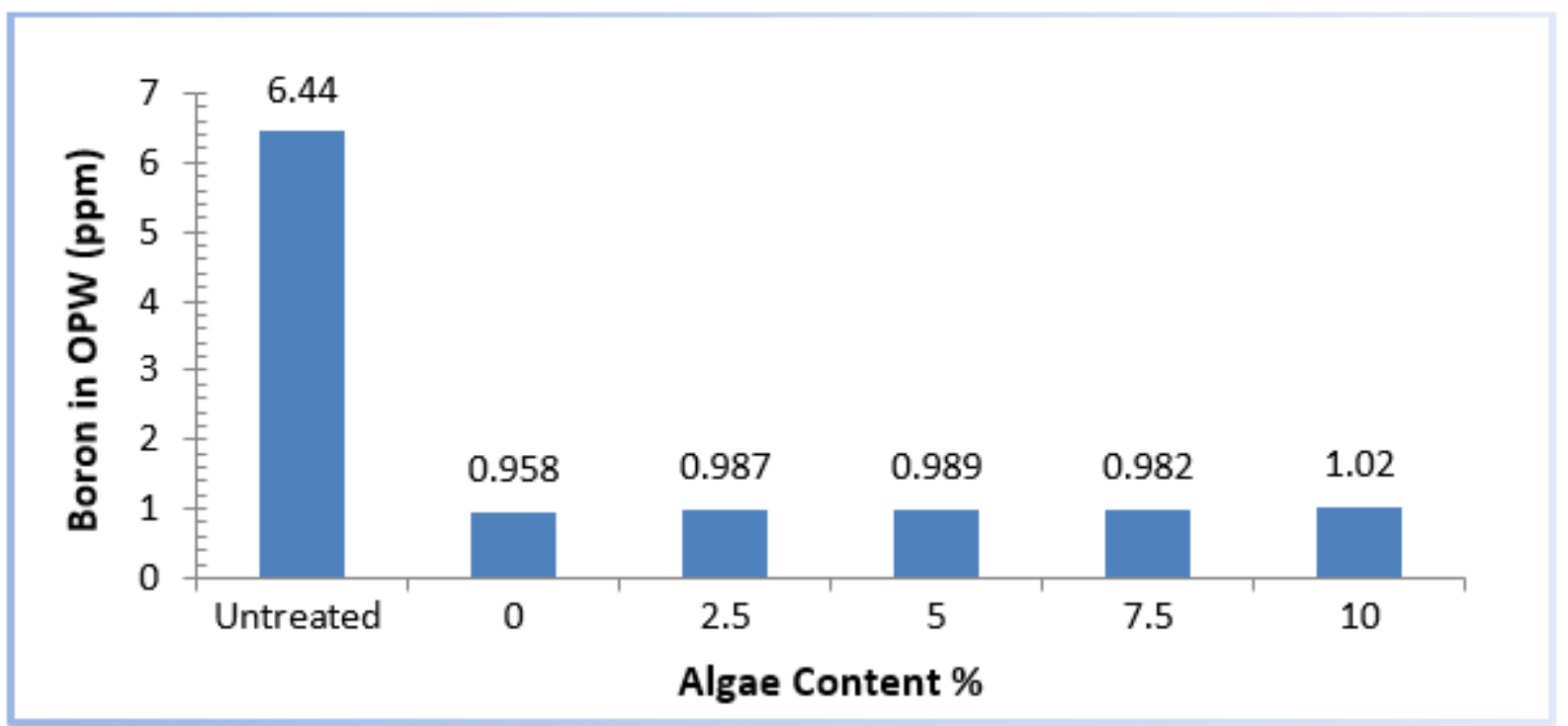

Figure 4

Boron content in OPW after adsorption on PU/algae composites 